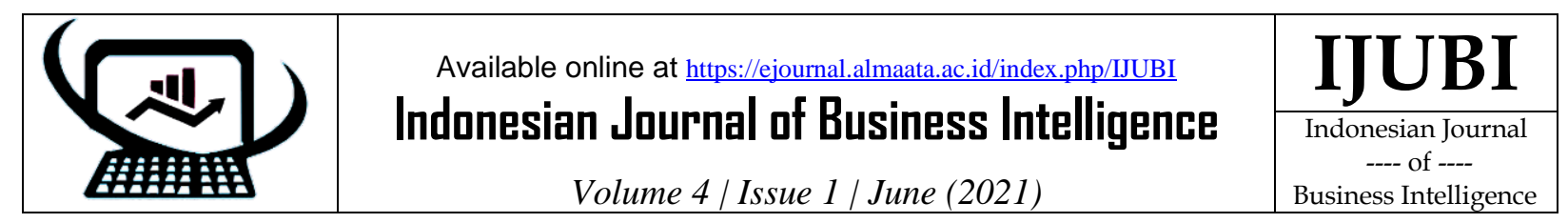

\title{
IMPLEMENTASI SISTEM REMINDER JADWAL CUCI DARAH PADA PASIEAN HEMODIALISIS DENGAN WHATSAPP GATEWAY
}

Muhammad Najamuddin Dwi Miharja ${ }^{1}$, Soma Setiawan Ponco Nugroho², Annafi' Franz ${ }^{3}$ ${ }^{1}$ Program Studi Teknik Informatika, Fakultas Teknik, Universitas Pelita Bangsa,

${ }^{2}$ Program Studi Sistem Informasi , Fakultas Sains dan Teknologi, Universitas Muhammadiyah Kudus,

${ }^{3}$ Program Studi Teknologi Rekayasa Perangkat Lunak, Politeknik Pertanian Negeri Samarinda. najamuddin.dwi@pelitabangsa.ac.id, somasetiawan@umkudus.ac.id, annafifranz@gmail.com

1J1. Inspeksi Kalimalang Tegal Danas. Cikarang Pusat,

2Jl. Ganesha I Purwosari Kudus 59316, Jawa Tengah,

3jl. Samratulangi Samarinda 75131

Keywords:

Reminder system, Whatsapp API, chronic kidney disease (CKD),

\section{Kata Kunci:}

Reminder system, Whatsapp API, chronic kidney disease (CKD),

Abstract
Every year, in March the second Thursday is World Kidney Day. Chronic kidney failure is a disease with the highest cost after heart disease. someone diagnosed to have chronic renal failure when the value of Glomerular Filtration Rate (GFR) is $<60 \mathrm{ml} /$ minute / $1.73 \mathrm{~m} 2$. So that have to hemodialysis therapy (HD) / dialysis usually twice a week with a duration of 4 hours each therapy. The increasing number of patients with chronic renal failure in their productive age who are relatively busy requires reminders so that they are not missed and come late so that it disrupts other patients' schedules. The dialysis schedule reminder system with whatsapp gateway is proven to help patients to be able to remind therapy times and come according to schedule. The system was built using the PHP programming language and node js for making the WhatsApp API and the MySQL DBMS for database storage.
Setipa tahun, pada bulan maret hari kamis minggu kedua adalah hari ginjal sedunia. Gagal ginjal kronik merupakan salah satu penyakit dengan biaya yang paling tinggi setalah penyakit jantung. Sesorang dikatakan mengalami gagal ginjal kronik ketika nilai Glomerular Filtration Rate (GFR) yakni < 60 $\mathrm{ml} /$ menit/1,73 m2. Sehingga harus menjalai terapi hemodialsisis (HD) / cuci darah biasanya seminggu dua kali dengan durasi 4 jam tiap terapi. Meningkatnya pasien dengan gagal ginjal kronik di usia produktif yang relatif sibuk membutuhkan pengingat supaya tidak terlewat dan telat datang sehingga meganggu jadwal pasien lain. Sistem reminder jadwal cuci darah dengan whatsapp gateway terbukti membantu pasien untuk bisa mengingatkan waktu terapi dan datang sesuai dengan jadwal. Sistem dibangun dengan menggunakan bahasa pemrograman PHP dan node $j s$ untuk pembuatan whatsapp API serta DBMS mysql untuk penympanan databasenya.

\section{Pendahuluan}

Setiap tahun, pada hari kamis minggu ke dua bulan maret merupakan hari ginjal sedunia. Penyakit ginjal kronis merupakan sebuah masalah kesehatan yang terjadi hampir di seluruh dunia dengan beban biaya yang sangat mahal.
Data pada tahun 2015 mencatat penyakit katatstropik menghabiskan biaya kesehatan sebesar 13,1 trilliun dan pada tahun 2016 meningkat menjadi 13,3 trilliun. Gagal ginjal merupakan penyaktik katastropik nomor 2 paling banyak menghabiskan biaysa kesehatan setlah penyakit jantung[1]. 
Seseorang dikatakan menderita Gagal Ginjal Kronik (GGK) adalah ketika terjadi penurunan Glomerular Filtration Rate (GFR) yakni < 60 $\mathrm{ml} /$ menit/1,73 m2 [2]. Pasien yang sudah dinyatakan gagl ginjal harus menjalani terapi hemodialisis atau cuci darah. Hemodilaisi (HD) merupakan terapi pengganti fungsi ginjal, pada umumnya dilakukan dua kali perminggu dengan waktu durasi kurang lebih 4 jam setiap hemodialisis. Pasien gagal ginjal kronik yang melakukan hemodilisis di dunia diperkirakan berjumlah 1,4 juta orang, sedangkan di Indonesia berdasarkan data Indonesian Renal Registry jumlah pasien di unit hemodialisis di tahun 2017 sebanyak 7.7892 orang[3].

Meningkatnya pasien HD dengan usia produktif dan kesibukanya serta keterbatasn jumlah mesin hemodialisis membutuhkan sebuah sistem yang mengigatk pasien hemodialisis untuk terapi dalam dua kali seminggu sehinggat tidak terlewatkan dan menggangu jadwah hemodialisis pasien lain.

Dengan kemajuan teknologi informasi dalam bidang komunikasi seperti whatsapp yang merupakan salah satu aplikasi pesan online yang paling banyak dipakai. Maka dibutuhkan sebuah sistem yang bisa membantu perawat hemodialisi dalam mengingatkan jadwal hemodialisi pasien yang berjalan otomatis dan bisa mengirim pesan setiap dua minggu sekali. Jadi tujuan dari penelitian ini adalah bagaimana mengaplikasikan sistem reminder jadwal cuci darah pada pasien hemodalisis dengan whatsapp gateway.

\section{Metode Penelitian}

Metode yang digunakan dalam pengembangan sistem di penelitian ini adalah Metode Rapid Application Development (RAD). Metode RAD menekanan pada pengembangan sistem yang relatif singkat dalam pengembangnya. Yang terdiri dari lima tahap yaitu analisa dan desain, desain user, pengujian, impelementasi dan evaluasi[4].

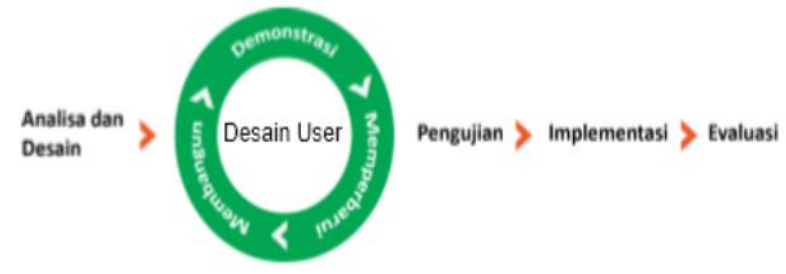

Gambar 1. Metode RAD

\section{Analisa dan desain}

Dalam tahap pertama ini dibagai menajdi dua yaitu tahap analisa kebutuhan dan desain sistem.

\section{a.Analisa kebutuhan}

pada tahap ini dilakaukan proses wawancara dan studi literatur tentang penelitian terdahulu. Di proses wawancara dilakaukan wawancara kepada para pasien $H D$ dan perawat HD tentang kebutuhan yang diperlukan dalam pembuatan aplikasi reminder dan mendapatkan masukkan untuk sistem yang kan diajukan, sedangkan tahap studi literatur adalah tahap mencari penelitian terdahulu seperti penelitian yang sudah diakukan oleh eveline marry yaitu membuat SMS reminder dan penjadwalan cuci darah bagia pasien hemodialisi[5]. Penelitian lain yaitu dilakukan oleh Fery Lusviana Widiany yang berjudul "Pemberian Sms Reminder Efektif Memperbaiki Status Gizi Antropometri Pasien Hemodialisis" pada tahun 2017[6].

Dalam kasus lain yaitu untuk pasien kanker yaitu kemoterapi, Sustin Farlinda pada tahun 2017 juga melakukan penelitian tentang pembuatan aplikasi pelayanan kemoterapi Rumah Sakit berbasis SMS gateway ysng mencakup data pendaftaran, data pasien dan dokter serta menu untuk mengirim SMS ke nomor pasien untuk mengingatkan jadwal kemoterapi[7].

Untuk masalah edukasi dan menambah pengetahuan tentang penyakit ini kepada pasien, tahun 2018 Ambar Relawati melakukan penelitian pada pasien HD di RS PKU Muhammadiyah tentang pembuatan aplikasi android dengan judul buku saku pasien dialysis dengan hasil bahwa aplikasi tersebut efektif meningkatkan pengetahuan pasien gagal ginjal kronis[8].

\section{b. Desain Sistem.}


Di dalam tahap desain sistem dilakuakn proses perancangan sistem seperi pembutan diagram konteks, data flow diagram dan pembuatan desain model database yang diperlukan.

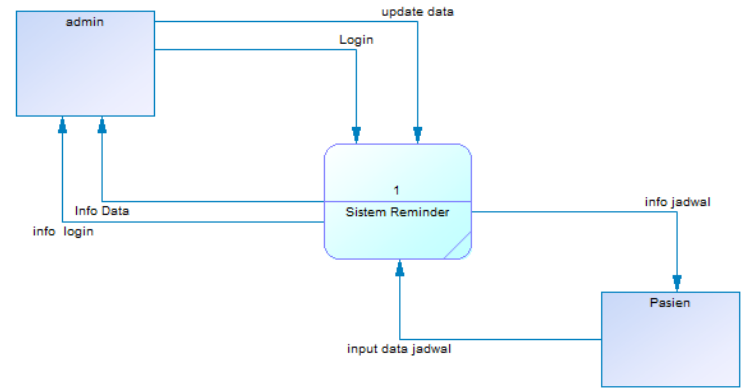

Gambar 2. Diagram konteks

Pada gambar diatas terdapat dua entitas yang dapat mengakases sistem yaitu pasien dan admin dalam hal ini bisa perawat dan admin HD. Admin bisa melakukan update data jadwaln dan data pasien, sedangkan pasien bisa daftar untuk memasukan data jadwalnya yang kemudian akan mendapatkan whatsapp reminder 1 jam sebelum waktu hemodialisis.

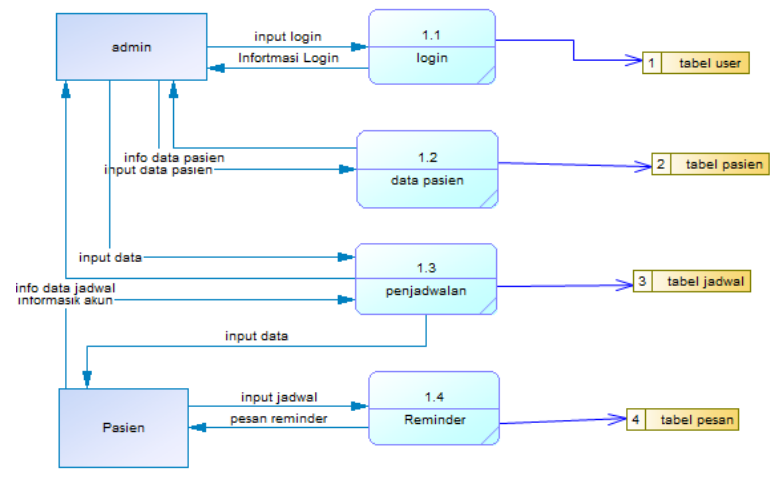

Gambar 3. Data flow diagram

Setelah pembuatan diagram konteks seperti gambar 2 diatas selanjutnya yaitu pembuatan data flow diagram yaitu gambaran tentang alur data yang terjadi dalam sistem dan akhirnya memunculkan banyaknya data store / tabel yang diperlukan dalam pembuatan sistem. Dalam gambar 3 diatas digambarkan terdapat 4 tabel yaitu tabel user untuk proses login, tabel pasien untuk menyimpan data pasien termasuk nomer whatsapp dan juga tabel jadwal serta terakhir yaitu tabel pesan reminder.

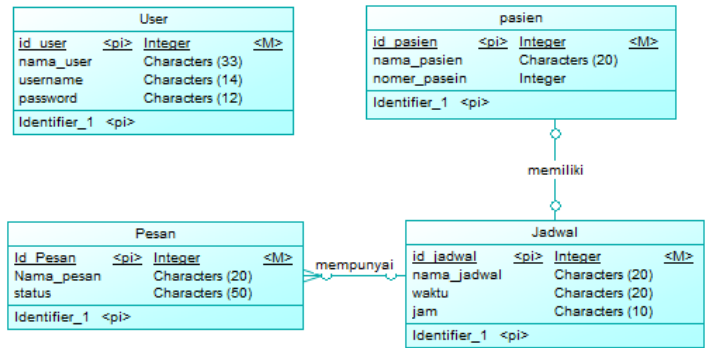

Gambar 4. Conceptual Data Model.

Gambar 4 merupakan Conceptual Data Model yaitu model gambran umum data yang akan dibuat sesuai desain dari gambar 3 yaitu 4 tabel tabel user, tabel pasien, tabel jadwal dan tabel pesan. Sedangkan relasi yang terjadi adalah pasien ke jadwal yaitu one to one. Danrelasi dari jadwal ke pesan adalah one to many artinya satu jadwal memiliki banyak pesan.

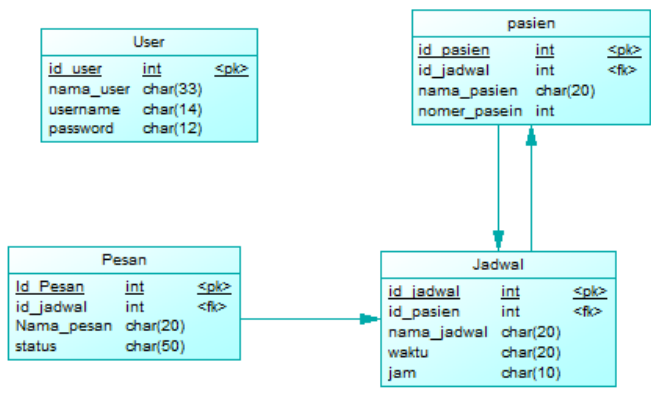

Gambar 4. Physical Data Model .

PDM adalah gambran bentuk fisik database yang akan dibuat dan juga lanjutan dari CDM. Di PDM sudah muncul foreign key yang merupakan bentuk relasi antar tabel. Dari PDM selanjutnya dibuat database di dalam mysql.

\section{Desain User (Pengguna)}

Dalam tahap ini dilakuakan proses penulisan program dan implementasi sistem. Yaitu proses penerjemahan desain dan perancangan ke dalam bahas pemrograman dan pembuatan sistem. Dalam pengembangan aplikasi ini menggunakan bahasa pemrograman PHP berbasis web dan node js untuk pembuatan gateway API wahtsapp. Sedangkan DBMS yang digunakan adalah mysql. 


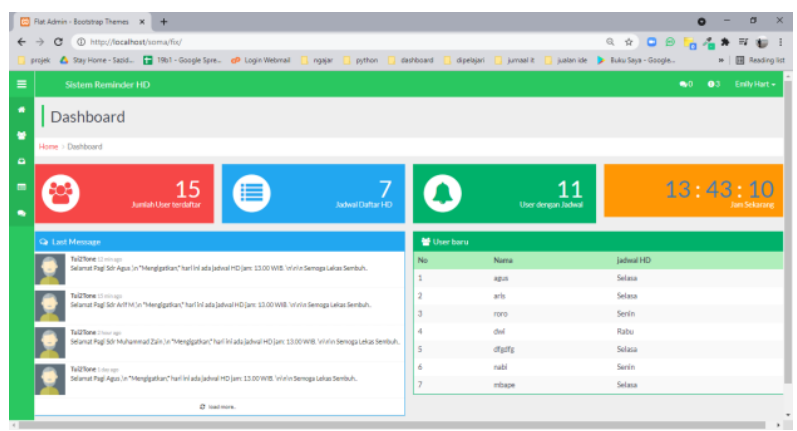

Gambar 5. Tampilan Home

Gambar diatas adalah tampilan dashboard admin, dalam tampilan dashboard ada informasi jumlah pasien, jumlah jadwal, informasi pesan terakhir serta informasi pasien yang baru daftar.

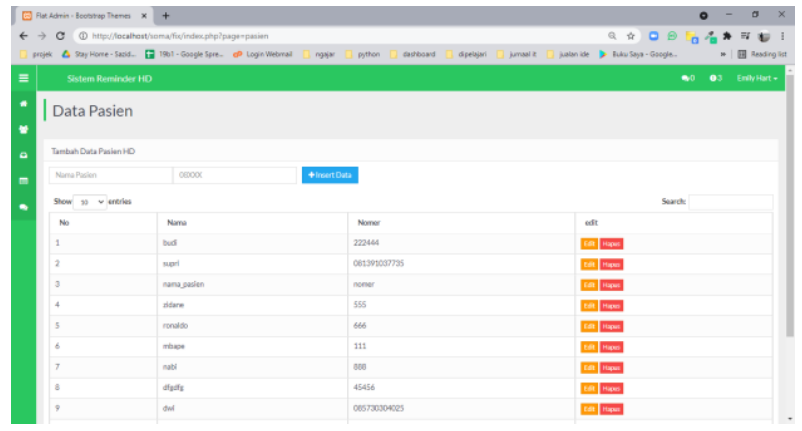

Gambar 6. Menu Data Pasien

Dalam menu ini admin data menambahkan dan mengupdate data pasien yang terdaftar dalam sistem.

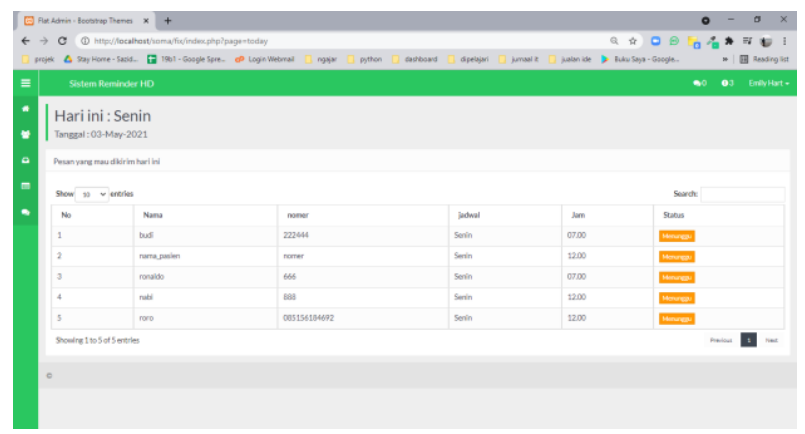

Gambar 8. Menu pesan yang akan dikirim

Dalam menu pesan ini admin dapat melihat pasien siapa saj yang mendapat jadwal hari itu dan informasi pesan apakah sudah terkirim atau gagal terkirim

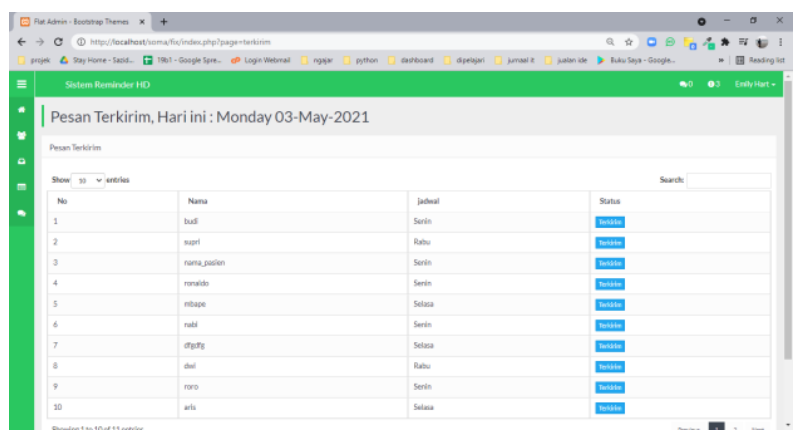

Gambar 9. Menu Pesan yang sudah terkirim

Di menu ini adalah informasi semua pesan yang sudah terkirim oleh sistem.

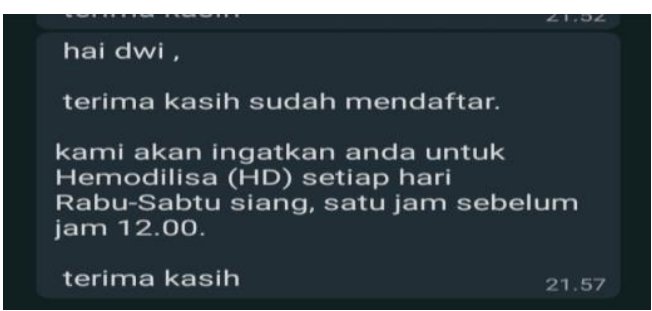

Gambar 10. Pesan setelah registrasi.

Gambar 10 adalah pesan yang dikirmkan kepada pasien setlah melakukan registrasi ke sistem. Setelah itu sistem akan mengirimkan pesan pengingat ke pasien dalam dua kali seminggu 1 jam sebelum jadwal yang telah dimasukkan. Seperti ditampilkan dalam gambar 11 di bawah ini.

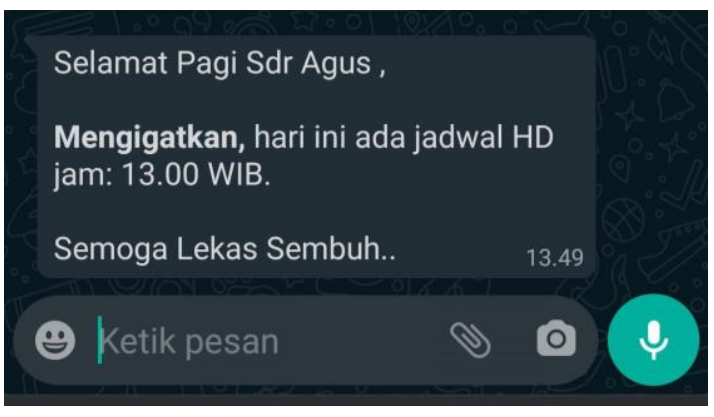

Gambar 11. Pesan reminder HD

\section{Kesimpulan dan Saran}

Setelah proses impelementasi dan pengujian kepada beberapa pengguna dapat disimpulkan pertama bahwa sistem reminder ini cukup mudah digunakan dan praktis untuk mengingtakan pasien Hemodilaisis dalam mengingtkan untuk terapi dua kali dalam seminggu. Kedua membantu perawat untuk manajemen jadwal HD dan termasuk membantu menkonfirmasi apabalia ada pasien yang tidk bisa datang karena ada halangan.

Dan saran pengembangan sistem selanjutnya adalah ditambahkan juga pengingat lain yaitu 
seperti pengingat minum obat, pembayaran BPJS serta pengingat perpanjangan surat rujukan faskes tingkat I (puskesmas dan klinik). serta pembuatan pesna pengingat saran makanan apa saja yang dibolehkan untuk menundukung diet makanan pada pasien gagal ginjal kronik.

\section{Referensi}

[1] Kementrian Kesehatan (Kemenkes). Hari Ginjal Sedunia 2018: “Kidneysand Women's Health: Include, Value, Empower. 2018

[2] Black M. Joyce., Hawks H. Jane. Medical surgical nursing:clinical management for positive outcome. Volume 1. Eigth Edition. Saunders Elsevier. St. Louis. Missouri. 2019

[3] Indonesian Renal Registry (IRR). 10th Report of Indonesian Renal Registry (2017). Perhimpunan Nefrologi Indonesia (PERNEFER I). 2017

[4] TR. S. Pressman, Software Engineering: A Practitioner's Approach, Seventh Edition, 7th Editio., vol. 9781118592. New York: The McGraw-Hill Companies, 2010.
[5] Mary, Eveline. Sevani, Nina. "SMS Reminder dan Penjadwalan Cuci Darah Bagi Paisen Hemodialisis". Teknik Informatika. Fakultas teknik dan Ilmu Komputer, Universitas Kristen Krida Wacana. Jakarta.2013.

[6] Widiany. Fery L. Afriani, Yuni, "pemberian SMS Reminder Efektif memperbaiki Status Gizi Antropometri Pasien Hemodialisis". Jurnal Ilmu Gizi Indonesia. Volume 01, Issue 01. 2017

[7] Farlinda, Sustin, Karimah, Rinda Nurul. Putri, Eva Dwiana. "Pembuatan Aplikasi Pelayanan Kemoterapi Rumah Sakit berbasis SMS Gateway". Jurnal Manajemen Informasi kesehatan Indonesia. Volume 5 issue 2. 2017.

[8] Relawati, Ambar. Syafriati, Ani, Al Hasbi, Habib. Fitria, Pipit Nur. "Edukasi pasien chronic kidney disease berbasis aplikasi andorid : buku saku pasien dialysis". Jurnal Health of Studies. Volume 3. No 2. 2018 